\title{
Exclusive Breastfeeding Practice Among Lactating Mothers Infected with HIV in Southern Highlands of Tanzania, Assessing the Prevalence and Factors Associated with the Practice; An Analytical Cross-Sectional Study
}

Fabiola Vincent Moshi ( $\nabla$ fabiola.moshi@gmail.com )

University of Dodoma School of Nursing and Public Health https://orcid.org/0000-0001-8829-2746

Rose Faustine

University of Dodoma School of Nursing and Public Health

\section{Research}

Keywords: Exclusive breastfeeding, exposed infants, and HIV

Posted Date: July 26th, 2021

DOI: https://doi.org/10.21203/rs.3.rs-696441/v1

License: () (1) This work is licensed under a Creative Commons Attribution 4.0 International License. Read Full License 


\section{Abstract}

\section{Background:}

There is no other better way proven to safeguard an infant's health in the first six months of life than Exclusive Breast Feeding (EBF). Mother's breast milk is valuable in all aspects of an infant's physical and mental growth as well as immune development. The study aimed at assessing the prevalence and factors associated with EBF practice among lactating HIV-infected mothers in the Southern Highlands of Tanzania.

Method: A hospital-based analytical cross-sectional study was conducted among lactating HIV-infected mothers. A random sampling procedure was used to obtain 372 HIV-infected mothers of infants of 6 to 12 months who were still breastfeeding at the time of data collection. An interviewer-administered structured questionnaire was used for data collection. Bivariate and multivariate logistic regression was used to assess factors associated with EBF practice. Statistical package for social science (SPSS v.20) software was used for data entry and analysis.

Results: The prevalence of EBF practice was $58.1 \%$ at $95 \%$ Confidence Interval of $52.9 \%$ to $63.1 \%$. More than half of the respondents $199(53.5 \%)$ had adequate knowledge while 173(46.5\%) had inadequate knowledge on EBF. After adjusted for confounders, factors associated with EBF practice were knowledge on EBF [Adequate knowledge ( $A O R=5.114$ at 95\% $\mathrm{Cl}=3.2-8.172, p<0.001)$ ], ANC visit [ Adequate $(\mathrm{AOR}=1.756$ at $95 \% \mathrm{Cl}=1.094-2.817, \mathrm{p}=0.002)$ ], Income per day [1 Or more USD ( $\mathrm{AOR}=1.828$ at $95 \% \mathrm{Cl}=1.136-2.943, \mathrm{p}=0.013)$ ], perception towards $\mathrm{EBF}$ [ positive perception $(\mathrm{AOR}=3.506$ at $95 \% \mathrm{Cl}=2.248$ $5.468, \mathrm{p}<0.001$ ) and ever experienced breast problem $\mathrm{AOR}=3.908$ at $95 \% \mathrm{Cl}=1.891-8.075, \mathrm{p}<0.001$

Conclusion: More than half of interviewed mothers practiced EBF. The EBF practice among HIV lactating mothers was significant influenced by adequate knowledge on EBF, positive perception toward EBF, adequate ANC visits, and having never experienced breast problems. Strengthening adherence to ANC routine visits, counseling on breastfeeding, and improving mother's knowledge of exclusive breastfeeding would contribute to the enhancement of EBF practice in this region. An innovative interventional study is recommended to come up with an effective strategy to improve EBF knowledge among HIVinfected mothers.

\section{Background}

Human immunodeficiency virus (HIV) is a virus that abates the body immune of a person and exposing the body to several opportunistic infections [1]. Albeit the major means of virus transmission is via unprotected sex, a significant majority of transmission occurs from mother to child. Mother-to-child transmission happens when HIV is transmitted from the mother to the child in the uterus, during birth, or while breastfeeding [1]. Exclusive breastfeeding (EBF) is the process in which the infant gets only breast milk and nothing else, except for ORS, minerals, vitamins, and medicines [2]

HIV and EBF have become important parameters today. It is estimated that about 37.9 million people were HIV positive by the end of 2018 . Similarly, 1.7 million people became newly infected with HIV in 2018 globally [3]. For African Region, WHO observed that in the same year, there was an acute problem whereby there were about 25.7 million people affected with HIV infection [3].

Breastfeeding is one of the factors cited in the literature to contribute to the transmission of HIV to breastfeeding babies. However, exclusive breastfeeding for six months after birth has been found to lower the risk. Globally, it is estimated that $34.8 \%$ of infants were fully breastfed in the first 6 months of life [4]. In subSaharan Africa, the prevalence of EBF to both HIV-positive mothers and negative is low as to $36 \%$ [4]. In Tanzania, EBF up to the first six months at the national level has shown to raise from $49 \%$ in 2010 to $59 \%$ in 2015 [5]. While the study was conducted in Ilala municipal, Tanzania the prevalence of exposed infants who were EBF was $46 \%$ [6].

Breastfeeding has a significant function in the nutrition, health, and cognitive growth of infants because human milk is the perfect nutrition for infants' survival, development, and growth [6. If infants get well breastfed in the first six months of life, their immune system becomes strengthened. A strengthened immune system protects them from diseases that cause infant mortality [7,8]. With exclusive breast-breastfeeding (i.e. not mixing it with other feeds), the risk of HIV transmission is lowered [9].

The first breast milk (colostrum) gives the newborn natural protection from the mother to avert infections. This is to say that infants need exclusive breastfeeding for the first six months of life to achieve optimal growth and development (10). Research shows that EBF, when applied for the first 6 months of a baby's life, lowers the risk of MTCT by 3-4times when compared to mixed breastfeeding [9]. HIV transmissions have been revealed to influence family choices on infant breastfeeding methods despite government policy such as maternal age, HIV stigma, education of the mother, economic factors, and cultural beliefs on breast milk $[9,11]$.

According to WHO guidelines, the baby must be exclusively breastfed for the first six months. Moreover, WHO emphasized EBF even if ARV medications are not accessible unless the environment and social circumstances do not allow or it allows for safe and supportive replacement breastfeeding [2]. Concerning Tanzania guidelines, HIV-positive mothers should exclusively breastfeed for the first six months of life then introduce complementary foods while continuing to breastfeed up to 12 months and after six weeks these infants should be checked for their serological status even if the results were negative. A rapid test should be done at 18 months to confirm their serological status as at this time maternal HIV antibodies would have diminished [12].

EBF among HIV-infected mothers can be hindered by several factors. Studies documented such factors as primiparity, maternal systemic illness, stigma, women's employment [14]. Some women living with HIV infection lacked adequate counseling on EBF. Similarly, a culture of mixed breastfeeding norms has been reported as a barrier [14,15]. Having inadequate knowledge and a negative attitude on EBF have also been found to impede EBF practice among HIVinfected nursing [4]. Some studies in Tanzania identified different factors; advanced maternal age and insufficient milk [15]. Two studies conducted in Tanzania, further noted fear of transmitting HIV to the baby, fear of disclosure, and maternal underweight contributed to inadequate EBF practice [6,16]. 
Studies have further revealed the negative attitude of mothers to EBF to have been connected to some myths. For example, HIV lactating mothers believed EBF as very difficult to the mother's body, and that EBF has the potential of weakening their health, lowering their blood quantity, fear of spreading HIV to their infants, and fear of getting infants who are often sick than if they did not exclusively breastfeed. some women also believed that practicing EBF could lower their immunity [17].

Efforts did by the government to encourage baby-friendly hospital initiative breastfeeding campaigns and breastfeeding commemoration day every August yearly, and provision of three months maternity leave to employed women, still, EBF is a problem of concern in Tanzania. This necessitated the need to conduct a study on prevalence and factors associated with EBF practice lactating HIV-infected mothers in the Southern Highlands of Tanzania.

\section{Method \\ Study Setting}

The study was conducted in the Southern Highland Zone (Iringa and Njombe) regions. Iringa Region is served by a total of 36 health facilities, of which 13 are hospitals and 23 health centers. All these health facilities provide CTC and PMCTC services. The Iringa Region borders the dry belt of central Tanzania in the north and south by Lake Nyasa. It lies between latitudes $7^{\circ} 05^{\circ} 32$ and 12 South and longitude $33^{\circ} 47^{\circ} 32$ to 36 East of the meridian. Iringa Region is contiguous with the Dodoma and Singida regions in the North, Mbeya to the west, and Morogoro in the East, and Ruvuma in the South. Lake Nyasa separates Iringa and Malawi in southwestern Tanzania. It has six districts with a population of 941,238 based on the Tanzania national census 2012 [18].

Njombe Region is among the 31 managerial regions of Tanzania. It was officially registered in March 2012, from the Iringa region as an independent region. The 2012 national census shows that the population of Njombe is 702,097[18]. The region is bounded by Mbeya Region South-east about $100 \mathrm{~km}$. The northern end is well marked in $8^{\circ} 50^{\prime} \mathrm{S}$ by an escarpment falling to the Usangu plains, the eastern branch of the East African rift valley, and the basin of the Great Ruaha River. Southwards the range terminates in the deep valley of the Ruhuhu river in $10^{\circ} 30^{\prime} \mathrm{S}$, the first decided break in the highlands that is reached from the north along the east coast of Lake Malawi.

These regions are estimated to have the highest HIV prevalence whereby $16.5 \%$ of adults are infected in Njombe and 19.2\% in Iringa [18]. These two regions have therefore been selected because of the remarkably high prevalence of HIV.

\section{Study Design}

A hospital-based analytical cross-sectional study employed a quantitative approach was used. The study population comprised of HIV-positive lactating mothers attending the PMCT program at Iringa and Njombe Regions.

\section{Inclusion Criteria}

All HIV-positive lactating mothers with an infant aged 6 to 12 months who were attending the PMCT program during data collection were included.

\section{Exclusion Criteria}

All HIV-positive lactating mothers with very seriously ill children who were not able to concentrate on answering the questions were excluded from the study. Mothers diagnosed with cognitive or psychiatric conditions were also excluded as their level of comprehension would be limited. HIV-positive lactating mothers who were very seriously sick at the time of data collection were excluded as body weakness would result in the inability to not being able to go through all questions comprehensively.

\section{Sample Size}

The sample size was estimated by using the Kish Leslie formula (1965).

Formula: $\mathrm{n}=(\mathrm{Z})^{2} \mathrm{P}(1-\mathrm{P}) / \mathrm{e}^{2}$

Where,

$\mathrm{n}=$ the required minimum sample size

Z= constant standard normal deviate (1.96\% confidence level)

$\mathrm{P}=$ estimated prevalence of HIV positive mothers who breastfeed exclusively up to 6 months of infants age which is $46 \%$ as per study by [6].

$\mathbf{e}=$ margin of error on $\mathrm{p}$ (set at 5)

Whereby $Z=1.96$

$P=46 \%=0.46$ 
$e=5 \%=0.05$

$\mathrm{n}=(1.96)^{2} \times(0.46)(1-0.46) /(0.05)^{2}=0.95425344 / 0.0025=372$

Therefore, the actual sample size for this study was $\mathbf{3 7 2}$ HIV lactating mothers.

\section{Sampling Technique}

The Census method was used to include regional hospitals that are Iringa and Njombe Regional hospital. In other health facilities simple random procedure was employed whereby in Iringa there are six districts out of these only 3 were selected by lottery replacement method after that one hospital was selected from each district using the lottery replacement method, and two health centers from each district. The same procedure of simple random method by lottery replacement was used in Njombe Region whereby three districts out of six were selected; one hospital was selected from each district using the lottery replacement method, and two health centers from each district. Then, systematic random sampling was employed in which the first round of HIV-positive lactating mothers was identified from the clinic registration. In the second round, calculation of the $\mathrm{K}^{\text {th }}$ interval was done using the $\mathrm{K}^{\text {th }}$ formula to select mothers who were invited to participate in the study.

$\mathrm{K}^{\text {th }}=\mathrm{N} / \mathrm{n}$

Whereby,

$\mathbf{N}=$ total population units

$\mathbf{n}=$ sample size

In this study, the total population of HIV lactating mothers was 963 and the sample size was 372

963/372=2.5 therefore the sampling interval included every second HIV lactating mother.

\section{Data Collection Technique and Tool}

The data for this study was gathered through face-to-face interviewer-administered structured questionnaires adapted and modified from [6,19,20]. Data were collected by two trained research assistants and the principal investigator. Standard structured questionnaires were then translated by the language teacher to Kiswahili which the language is spoken by study participants. The Kiswahili version questionnaire was used. Since data collection was done during COVID-19 precaution against protection was ensured all researcher assistants, principal investigator, and the study participants used sanitizer and masks, as well as one meter between the study participants was observed.

\section{Variables and its Measurements}

\section{Dependent Variables}

Exclusive Breastfeeding status was measured by nominal scale as exclusive breastfeeding practices and non-exclusive breastfeeding practices as continuous breastfeeding since birth such as starting to provide the baby with breast milk within the first hour after delivery, breastfeeding on demand day and night, and continuous breastfeeding alone up to 6 months.

\section{Independent variables}

Socio-demographic Characteristic: comprised 19 questions and were measured by nominal scale i.e. residence, education, marital status, occupation, a model of delivery, place of delivery, counseling on EBF whereby age, and income, were measured by an ordinal scale.

Knowledge on exclusive breastfeeding was measured by a nominal scale involving 12 questions, with yes/no answers which were then converted into correct and incorrect. The total score was obtained and computed for mean to categorize it into adequate and inadequate knowledge. The mean score of knowledge on EBF among lactating mothers was 7.66 the maximum score being 12 points while the minimum score was 1 point. A score below the mean was considered inadequate knowledge and above the mean adequate knowledge.

\section{Perceived Benefits of exclusive breastfeeding}

Perception towards EBF was measured using 5 points Likert scale. 13 questions were used to determine the perception of mothers. The order of scoring for positive statements was strongly agree $=5$, agree $=4$, undecided $=3$, strongly disagree $=2$, disagree $=1$ and vice versa for negative statement. The total score was obtained and computed for mean and then categorized into positive and negative perceptions.

The mean score of perception on EBF among lactating mothers was 41.38 the maximum score being 60 points while the minimum score was 22 points. A score above the mean was regarded as a positive perception, while a score below the mean was considered as a negative perception.

Page $4 / 12$ 


\section{Data Analysis}

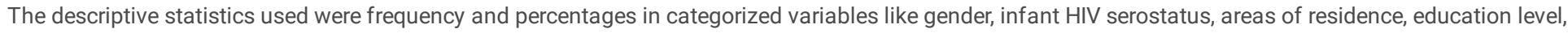

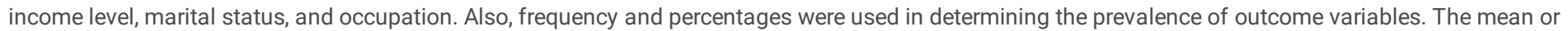

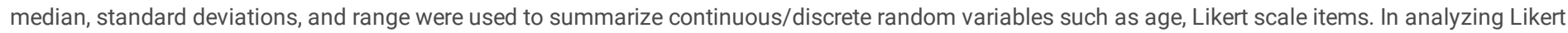

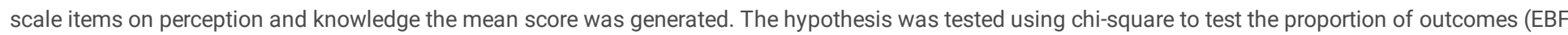
practices) across different exposures.

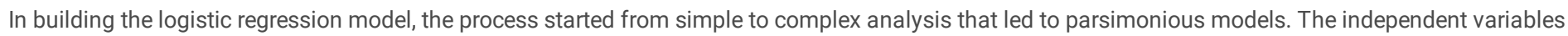

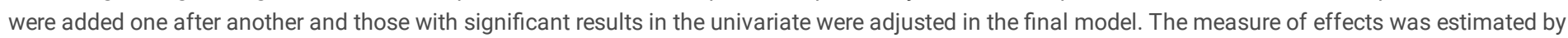
the Odds ratio and was tested at a $95 \%$ confidence interval and a $5 \%$ significance level

\section{Results}

\section{Social-demographic characteristics}

This study included 372 breastfeeding women who had been diagnosed with HIV infection before or during pregnancy. Their mean age was $30.66 \pm 5.72$ (range 18-49) and that of their children at the time of data collection was $9.74 \pm 2.08$ (range 6-12 months). Socioeconomically, most of the women were married $337(90.6 \%)$ lived at or less than one USD per day $207(55.6 \%)$, and had primary level of education $199(53.5 \%)$ (Table 1) 
Table 1

social-demographic Distribution of the Respondents $(\mathrm{N}=372)$

\begin{tabular}{|c|c|c|}
\hline Variables & Frequency(n) & Percentages (\%) \\
\hline \multicolumn{3}{|l|}{ The age group of the mother } \\
\hline Below 20 years & 16 & 1.6 \\
\hline $20-34$ years & 265 & 71.2 \\
\hline $35-49$ years & 101 & 27.2 \\
\hline \multicolumn{3}{|l|}{ Education level } \\
\hline No formal education & 14 & 3.8 \\
\hline Primary & 199 & 53.5 \\
\hline Secondary & 141 & 37.9 \\
\hline College & 18 & 4.8 \\
\hline \multicolumn{3}{|l|}{ Residence } \\
\hline Rural & 195 & 52.4 \\
\hline Urban & 177 & 46.6 \\
\hline \multicolumn{3}{|l|}{ Occupation } \\
\hline Employed & 48 & 12.9 \\
\hline Self-employment & 157 & 42.2 \\
\hline Housewife & 167 & 44.9 \\
\hline \multicolumn{3}{|l|}{ The average income per day } \\
\hline One Us dollar & 207 & 55.6 \\
\hline Less than one dollar & 165 & 44.4 \\
\hline \multicolumn{3}{|l|}{ Marital status } \\
\hline Married & 337 & 90.6 \\
\hline Unmarried & 35 & 9.4 \\
\hline \multicolumn{3}{|l|}{ Sex of the child } \\
\hline Female & 200 & 53.8 \\
\hline Male & 172 & 46.2 \\
\hline \multicolumn{3}{|l|}{ Place of delivery } \\
\hline Hospital delivery & 369 & 99.2 \\
\hline Home delivery & 3 & 0.8 \\
\hline \multicolumn{3}{|l|}{ Mode of delivery } \\
\hline Spontaneous vaginal delivery & 305 & 82 \\
\hline Caesarean section & 63 & 16.9 \\
\hline Assisted delivery & 4 & 1.1 \\
\hline \multicolumn{3}{|l|}{ Counselled on EBF } \\
\hline Counselled on EBF & 371 & 99.7 \\
\hline Not counselled on EBF & 1 & 0.3 \\
\hline \multicolumn{3}{|l|}{ Attended ANC } \\
\hline Inadequate visit & 138 & 37.1 \\
\hline Adequate visit & 234 & 62.9 \\
\hline
\end{tabular}

\section{Knowledge of Breastfeeding Practice}

The findings showed that $348(96.2 \%)$ of respondents knew that breast milk was cheap and available and that the baby should be breastfed in demand $290(78.0 \%)$ and $352(94.6 \%)$ breast milk increases bonding between the mother and the baby. However, between $51 \%$ and $68 \%$ of the respondents could define 
EBF and knew that colostrum is nutritious to the infant, milk alone is sufficient to the infant in the first six months of life, EBF time is six months, breast milk protects the child from diseases and that EBF maintains mothers' body weight. The majority did not know that EBF acts as a contraceptive and that it reduces the risk of maternal breast cancer (Table 2).

Table 2

Rate score of knowledge on EBF among lactating mothers infected with human immunodeficiency virus in southern highland regions $(\mathrm{N}=372)$

\begin{tabular}{|c|c|c|}
\hline Knowledge on EBF & Incorrect n (\%) & Correct n (\%) \\
\hline Is the yellowish breast milk (colostrum) nutritious for the baby? & $119(32.0)$ & $253(68.0)$ \\
\hline Do you think breast milk alone is sufficient for the baby for $0-6$ months? & $121(32.5)$ & $251(67.5)$ \\
\hline Should the baby be breastfed on demand? & $82(22.0)$ & $290(78.0)$ \\
\hline The appropriate time to start complementary foods is soon as the baby starts the seventh month? & $140(37.6)$ & 232(62.4) \\
\hline Does breast milk increase bonding between the mother and the baby? & $20(5.4)$ & $352(94.6)$ \\
\hline Is it true that breast milk is cheap and available? & 14(3.8) & $358(96.2)$ \\
\hline Exclusive breastfeeding act as a Contraception method? & 232(62.4) & $140(37.6)$ \\
\hline
\end{tabular}

\section{Knowledge of exclusive breastfeeding practice}

The mean score of knowledge on EBF among HIV lactating mothers was 7.66, the maximum score being 12 points while the minimum score being 1 point. More than half of the respondents 199(53.5\%) had adequate knowledge while 173(46.5\%) had inadequate knowledge on EBF.

\section{Perception of EBF among Lactating Mothers Infected with Human Immunodeficiency Virus}

The mean score for the perception of EBF among HIV lactating mothers was 41.38 . The maximum score was 60 points while the minimum score was 22 points out of all respondents ( $\mathrm{N}=372)$, positive perceptions were 194(52.2\%), and negative perception 178(47.8\%).

\section{Prevalence of EBF practice among lactating HIV infected mothers}

The prevalence of EBF practice was $58.1 \%$ at a $95 \%$ Confidence Interval of $52.9-63.1 \%$. More than half of the respondents 216 ( $58.1 \%$ ) had exclusively breastfed their infants for the first six months while 156(41.9\%) did not breastfeed their infants exclusively in the first six months

\section{The relationship Lactating mothers' characteristics and EBF practice}

By cross-tabulation, there was a significant relationship between knowledge on EBF and the practice of EBF $(p<0.001)$ in which those who had adequate knowledge were most likely practicing EBF. Other variables that showed a significant relationship were the income of a mother $(p=0.002)$, level of education of a mother $(p=0.007)$, and antenatal visits $(p<0.001)$, perception towards EBF $(p<0.001)$, and ever experienced breast problem $(p<0.001)$ refer to Table 3 . 
Table 3

The relationship between knowledge on EBF and EBF Practice

\begin{tabular}{|c|c|c|c|c|}
\hline Variables & EBF f (\%) & No EBF $f(\%)$ & $x^{2}$ & p-value \\
\hline \multicolumn{5}{|c|}{ The age group of the mother } \\
\hline Below 20 years & $4(66.7)$ & $2(33.3)$ & & \\
\hline $20-34$ years & 157(59.2) & $108(40.8)$ & & \\
\hline $35-49$ years & $55(54.5)$ & $46(45.5)$ & 0.874 & 0.646 \\
\hline \multicolumn{5}{|l|}{ Sex of the child } \\
\hline Male & $104(60.5)$ & $68(39.5)$ & & \\
\hline Female & $112(56.0)$ & $88(44.0)$ & 0.757 & 0.384 \\
\hline \multicolumn{5}{|l|}{ Income per day } \\
\hline 1USD & $135(65.2)$ & $72(34.8)$ & & \\
\hline$<1$ USD & $81(49.1)$ & $84(50.9)$ & 9.806 & 0.002 \\
\hline \multicolumn{5}{|l|}{ Level of education } \\
\hline No formal education & $4(28.6)$ & $10(71.4)$ & & \\
\hline Primary & $106(53.3)$ & $93(46.7)$ & & \\
\hline Secondary & $95(67.4)$ & $46(32.6)$ & & \\
\hline College & $11(61.1)$ & $7(38.9)$ & 11.972 & 0.007 \\
\hline \multicolumn{5}{|l|}{ Occupation } \\
\hline Employed & $30(65.5)$ & 18(37.5) & & \\
\hline Self-employed & $96(61.1)$ & $61(38.9)$ & & \\
\hline Housewife & $90(53.9)$ & $77(46.1)$ & 2.194 & 0.334 \\
\hline \multicolumn{5}{|l|}{ Residence } \\
\hline Rural & $108(55.4)$ & $87(44.6)$ & & \\
\hline Urban & $108(61.0)$ & $69(39.0)$ & 1.209 & 0.272 \\
\hline \multicolumn{5}{|l|}{ Mode of delivery } \\
\hline Normal delivery & 181(53.3) & $124(40.7)$ & & \\
\hline Cesarean section & $34(54)$ & $29(46)$ & & \\
\hline Assisted delivery & $1(25)$ & $3(75)$ & 2.435 & 0.296 \\
\hline \multicolumn{5}{|l|}{ Counseled on EBF } \\
\hline Yes & $216(58.2)$ & $155(41.8)$ & & \\
\hline No & $0(0.0)$ & $1(100)$ & 1.388 & 0.239 \\
\hline \multicolumn{5}{|l|}{ ANC VISIT } \\
\hline Inadequate visit & $64(46.4)$ & $74(53.6)$ & & \\
\hline Adequate visit & $152(65.0)$ & $82(35.0)$ & 12.308 & $<0.001$ \\
\hline \multicolumn{5}{|l|}{ Knowledge categories } \\
\hline Inadequate knowledge & $64(37.0)$ & $109(63.0)$ & & \\
\hline Adequate knowledge & $152(76.4)$ & $47(23.6)$ & 58.964 & $<0.001$ \\
\hline \multicolumn{5}{|l|}{ Perception of EBF } \\
\hline Negative & $102(57.3 \%)$ & $76(42.7 \%)$ & & \\
\hline Positive & $54(27.8 \%)$ & $140(72.2 \%)$ & 33.105 & $<0.001$ \\
\hline \multicolumn{5}{|c|}{ Experienced breast problem } \\
\hline Yes & 1 & & & \\
\hline No & 3.595 & 1.876 & 6.888 & $<0.001$ \\
\hline
\end{tabular}




\section{Factors associated with EBF Practice among lactating HIV infected mothers}

After adjusted for confounders, factors associated with EBF practice among lactating HIV infected mothers were knowledge on EBF [Adequate knowledge $(\mathrm{AOR}=5.114$ at $95 \% \mathrm{Cl}=3.2-8.172, \mathrm{p}<0.001)$ ], ANC visit [ Adequate $(\mathrm{AOR}=1.756$ at $95 \% \mathrm{Cl}=1.094-2.817, \mathrm{p}=0.002)$ ], Income per day [1 Or more USD $(\mathrm{AOR}=$ 1.828 at $95 \% \mathrm{Cl}=1.136-2.943, \mathrm{p}=0.013)$ ], perception towards $\mathrm{EBF}$ [ positive perception $(\mathrm{AOR}=3.506$ at $95 \% \mathrm{Cl}=2.248-5.468, \mathrm{p}<0.001)$ and ever experienced breast problem $\mathrm{AOR}=3.908$ at $95 \% \mathrm{Cl}=1.891-8.075, \mathrm{p}<0.001$ (Table 4).

Table 4

The Association between Knowledge on EBF and of EBF Practice

\begin{tabular}{|c|c|c|c|c|c|c|c|c|}
\hline \multirow[t]{2}{*}{ Variables } & \multirow[t]{2}{*}{ OR } & \multicolumn{2}{|l|}{$95 \% \mathrm{Cl}$} & \multirow[t]{2}{*}{ p-value } & \multirow[t]{2}{*}{ AOR } & \multicolumn{2}{|l|}{$95 \% \mathrm{Cl}$} & \multirow[t]{2}{*}{ p-value } \\
\hline & & Lower & Upper & & & lower & Upper & \\
\hline \multicolumn{9}{|l|}{ ANC Visits } \\
\hline Inadequate & 1 & & & & 1 & & & \\
\hline Adequate & 2.143 & 1.396 & 3.292 & $<0.001$ & 1.756 & 1.094 & 2.817 & 0.002 \\
\hline \multicolumn{9}{|l|}{ Knowledge on EBF } \\
\hline Inadequate & 1 & & & & 1 & & & \\
\hline Adequate & 5.508 & 3.513 & 8.636 & $<0.001$ & 5.114 & 3.200 & 8.172 & $<0.001$ \\
\hline \multicolumn{9}{|l|}{ Income per day } \\
\hline Less than 1USD & 1 & & & & 1 & & & \\
\hline 1 or more USD & 1.944 & 1.280 & 2.954 & 0.002 & 1.828 & 1.136 & 2.943 & 0.013 \\
\hline \multicolumn{9}{|l|}{ Level of education } \\
\hline No formal education & 1 & & & & 1 & & & \\
\hline Primary & 2.849 & 0.865 & 9.390 & 0.085 & 2.331 & 0.621 & 8.743 & 0.210 \\
\hline Secondary & 5.163 & 1.537 & 17.345 & 0.008 & 3.165 & 0.825 & 12.141 & 0.093 \\
\hline College & 3.929 & 0.879 & 17.563 & 0.073 & 1.401 & 0.266 & 7.382 & 0.691 \\
\hline \multicolumn{9}{|l|}{ Perceptions of EBF } \\
\hline Negative & 1 & & & & 1 & & & \\
\hline Positive & 3.480 & 2.259 & 3.361 & $<0.001$ & 3.506 & 2.248 & 5.468 & $<0.001$ \\
\hline \multicolumn{9}{|c|}{ Experienced breast problem } \\
\hline Yes & 1 & & & & 1 & & & \\
\hline No & 3.595 & 1.876 & 6.888 & $<0.001$ & 3.908 & 1.891 & 8.075 & $<0.001$ \\
\hline
\end{tabular}

\section{Discussion}

The prevalence of exclusive breastfeeding among exposed infants was found to be higher compared to a previous study in llala municipal council in Dar es Salaam, Tanzania [6] which is lower compared to the study done in Kilimanjaro only $0.2 \%$ of mothers practice exclusive breastfeeding [21]. However, the current study prevalence is lower than $63.4 \%$ reported in Ethiopia [22] and is lower than the $90 \%$ target recommended by the world health organization [2]. These differences could be attributed to the high HIV prevalence in the current study and design used in the previous studies. The time-lapse between the previous Tanzanian studies and the current one is five to eight years in which health promotion education might have improved the status quo of EBF.

The current results revealed that more than half of the respondents had adequate knowledge of exclusive breastfeeding but this is lower than what was found in one study conducted in Ethiopia whereby more than three-quarters of the respondents were knowledgeable on EBF[23]. This calls for an effort to improve this knowledge and these regions could benefit from strategies used in more successful settings such as Ethiopia. The fact that the Ethiopian study shows such a success and yet an African setting, is an encouragement that this is still possible in Tanzania.

The study further indicated that respondents with adequate knowledge of EBF practice were nearly two times more likely to practice EBF than their counterparts with inadequate knowledge. The results of the current study were consistent with studies done in Ethiopia and South Africa which reported that knowledgeable respondents were five times more likely to practice EBF[4,24]. The current and studies we refer to are evidence on the need to impart lactating mothers with knowledge for them to practice EBF. It also follows that adequate ANC attendance increased the odds of EBF practice by more than one time, especially among pregnant women who attended ANC services more than 4 times. Most women rely on ANC for necessary information on maternal and child 
health. It is therefore most likely that the level of knowledge on maternal and child health is dependent on ANC visits. This association between attendance to ANC, level of knowledge, and the practice of EBF have also been reported by Alebel et al. [25] in Ethiopia.

In this current study more than half of the respondents had a positive perception toward exclusive breasting feeding which has similarities and yet less than a report from another study in Ethiopia which reported that more than three-quarters of the respondents had a positive perception toward EBF[23]. The difference in perception could be attributed to the difference in the level of knowledge of EBF between the two settings. There are also sociocultural and belief differences that may affect how EBF is perceived from one setting to another. Sociocultural factors are also reported as the most predominant determinants of EBF in a study in South Africa [24]. It is important to create a positive belief/perception as shown in the health belief model that this is what ignites the process of change of behavior [26].

This is also evident in the current study where it is found that respondents with positive perceptions were four times more likely to practice EBF than those who had a negative perception. The finding of the present study was consistent with the study conducted in Ethiopia by Gebeyehu et al.[4] which noted that respondents who had positive perceptions were seven times more likely to practice EBF. Positive perception could be encouraged through counseling on infant feeding practice during ANC but also showing with example the consequences of not breastfeeding exclusively [4]. Again, following the Health Belief Model, pregnant and lactating women will most likely choose EBF if they are convinced that this is possible even within limited time and resources.

The present results revealed that the majority of respondents identified insufficient breast milk as a barrier to practicing EBF. The finding was similar to the study done by Maonga et al. [15] in Muheza Tanzania which reported that insufficient breast milk was one of the hindrances to practice EBF. However, the finding from these two Tanzanian studies is different from a report from South Africa showing that the most prominent barriers to EBF were cultural factors and influence from elders in the family [24]. Variation in predominating challenges to EBF is further seen as a study in Kenya (unlike Tanzania and South Africa) shows that stigma is the commonest barrier to EBF among HIV-infected lactating mothers [27].

The study further indicated that respondents who did not experience breast problems were three times more likely to practice EBF than their counterparts with breast problems. Breast problems were also identified as a barrier to EBF in another study in Nigeria [13]. Screening for breast conditions during pregnancy and lactation is therefore of paramount importance so that treatable conditions can be identified and given due management. This will likely increase the prevalence of EBF and improve infants' health.

In another study by Muhammed \& Seid [11], it was found that HIV -infected mothers who were employed were ten times more likely to be none exclusive breastfeeding than the unemployed. The current study did not find this as a significant barrier. These differences could be due to educational status with the current study majority had a primary level of education which means the study subjects did not differ so much in employment status. However, with the growing pace of women's education and the acquisition of full-time jobs, the means through which EBF can be promoted in this population ought to be considered.

Generally, it can be seen that barriers to EBF among HIV-positive lactating mothers are diverse and it would be so that they are also different even within the same country. It suggests that addressing these barriers should be setting specific and no intervention can fit all. There are also methodological differences between the studies such as varying sample sizes, tools for data collection, and design which could account for these differences.

\section{Conclusion}

More than half of interviewed mothers practiced EBF. The EBF practice among HIV lactating mothers was significant influenced by adequate knowledge on EBF, positive perception toward EBF, adequate ANC visits, and having never experienced breast problems. Strengthening adherence to ANC routine visits, counseling on breastfeeding, and improving mother's knowledge of exclusive breastfeeding would contribute to the enhancement of EBF practice in this region. An innovative interventional study is recommended to come up with an effective strategy to improve EBF knowledge among HIV-infected mothers.

\section{Abbreviations}

ANC Antenatal Clinic

ARV Anti Retral Viral

CTC Care and Treatment Centre

EBF Exclusive Breastfeeding

HBM Health Belief Model

HIV Human Immunodeficiency Virus

ID Identification

MSc Masters of Science

MTCT Mother to Child Transmission

ORS Oral Rehydration salt 
PMTCT Prevention of Mother to Child Transmission

RCH Reproductive Child Health

SDGs Sustainable Development Goals

UDOM University of Dodoma

UNAIDS United Nations Programme on HIV/AIDS

WHO World Health Organization

\section{Declarations}

\section{Ethics approval and consent to participate}

Approval to conduct the study was given by the University of Dodoma Research and Publication Committee. Government authorities at regional and council levels at Njombe and Iringa were contacted for Permission to conduct the study in both study regions. A written permit was obtained to conduct the study.

\section{Consent for publication}

Not applicable

\section{Competing interests}

The authors declare that had no conflict of interest

\section{Availability of data and materials}

The data and material used in the current study are available from the corresponding authors upon request.

\section{Funding}

This study was not funded.

\section{Acknowledgment}

We sincerely acknowledge the Ministry of Health, Community Development, Gender, Elder, and Children for financial support. We thank the administrative team of Southern highlands Regions for allowing us to conduct this study. We also thank our research assistants who had been helpful to us during data collection. We thank the facility leaders who allowed us to visit their facilities for data collection.

\section{Author's contributions}

RF conceptualized the study, did data collection, analysis and wrote the first draft of the manuscript while FM guided the conceptualization, analysis, and critical review of the manuscript. All authors read and consented to the manuscript to be submitted for peer review.

\section{References}

1. Kassa GM. Mother-to-child transmission of HIV infection and its associated factors in Ethiopia: a systematic review and. BMC Infect Dis. $2018 ; 1-9$.

2. WHO. Prevention of mother-to-child transmission (PMTCT) of HIV. 2018.

3. UNAIDS. Joint United Nations Programme on HIV/AIDS. Encycl Glob Heal [Internet]. 2019; Available from: https://www.unaids.org/sites/default/files/media_asset/2019-UNAIDS-data_en.pdf.

4. Gebeyehu N, Id G, Weldearegay HG, Mekango WKT, Woldemichael DE. ES, et al. Exclusive breastfeeding and associated factors among HIV positive mothers in. 2019;1-10.

5. Mgongo M, Hussein TH, Stray-Pedersen B, Vangen S, Msuya SE, Wandel M. Facilitators and Barriers to Breastfeeding and Exclusive Breastfeeding in Kilimanjaro Region, Tanzania: A Qualitative Study. 2019;2019.

6. Saka FJ. Factors Influencing Exclusive Breastfeeding among HIV Positive Mothers at llala Municipality-Dar es salaam. 2012.

7. Mgongo M, Mosha MV, Uriyo JG, Msuya SE, Stray-Pedersen B. Prevalence and predictors of exclusive breastfeeding among women in Kilimanjaro region, Northern Tanzania: a population-based cross-sectional study. 2013;1-8.

8. Bukola UA, Dairo MD, Fawole OI. Exclusive breastfeeding and HIV / AIDS: A crossectional survey of mothers attending prevention of mother-to-child transmission of HIV clinics in southwestern Nigeria. 2015;(November).

9. Yah CS, Tambo E. Journal of Infection and Public Health Why is mother to child transmission (MTCT) of HIV a continual threat to newborns in subSaharan Africa ( SSA ). J Infect Public Health. 2019;12(2):213-23.

10. Exavery A, Kanté AM, Hingora A, Phillips JF. Determinants of early initiation of breastfeeding in rural Tanzania. Int Breastfeed J. 2015;1-9. 
11. Muhammed OS, Seid KA. Determinants of none - exclusive breastfeeding practice among HIV-positive women at selected Health Institutions in Ethiopia: a case-control study. BMC Res Notes. 2019;1-6.

12. MoHCDGEC. National Guideline fo the Management of HIV and AIDS 7th Edition April. 2019. Development [Internet]. 2019;7(5,371,780,231.09):2,274,923,575.00-29.08. Available from:

https://www.differentiatedservicedelivery.org/Portals/0/adam/Content/NqQGryocrU2RTj58iR37uA/File/NATIONAL_GUIDELINES_FOR_THE_MANAGEMEN

13. Tomlinson M, Osawe S, Kagee A, Africa S. barriers to and facilitators of adherence to exclusive breastfeeding practices among HIV infected and noninfected women in Jos, Nigeria. Maternal Child Heal. 2017;21(4):953-60.

14. Cuinhane CE, Coene G, Roelens K, Vanroelen C. AIDS \& Clinical Research Exploring Perceptions and Practices of Biomedical Norms during Exclusive Breastfeeding among HIV-Positive Lactating Mothers in. 2017;8(4):9-10.

15. Maonga AR, Msuya SE, Damian DJ. Factors Affecting Exclusive Breastfeeding among Women in Muheza District Tanga Northeastern Tanzania: A MixedMethod Community Based Study. Matern Child Health J. 2016;20(1):77-87.

16. Manji KP, Duggan C, Liu E, Bosch R, Kisenge R, Aboud S, et al. Exclusive breastfeeding protects against mother-to-child transmission of HIV-1 through 12 months of age in Tanzania. J Trop Pediatr [Internet]. 2016;62(4):301-7. Available from: https://watermark.silverchair.com/fmw012.pdf? token=AQECAHi208BE490oan9kkhW_Ercy7Dm3ZL_9Cf3qfKAc485ysgAAAtwwggLYBgkqhkiG9w0BBwagggLJMIICxQIBADCCAr4GCSqGSIb3DQEHATAeBc f1VdWw1ab9AgEQgIICj031cX7l3WXxiZz9Vn0v3l1AHtffre.

17. Kafulafula U, Hutchinson MK, Gennaro S, Guttmacher S. Maternal and health care workers ' perceptions of the effects of exclusive breastfeeding by HIVpositive mothers on maternal and infant health in Blantyre, Malawi. 2014;(November).

18. National Bureau of Statistics (NBS), Office of Chief Government Statistician (OCGS). Population Distribution by Age and Sex: The United Republic of Tanzania. 2013;471. Available from: http://ihi.eprints.org/2169/1/Age_Sex_Distribution.pdf.

19. Ali NS. Prevalence of Exclusive Breastfeeding among Infants under 6 months Old Attending Mnazi Mmoja Hospital Zanzibar. 2016.

20. Boateng MF. Knowledge, Attitude and Practice of Exclusive Breastfeeding among Mothers in Techiman, Ghana. 2018;(May).

21. Hussein TH, Mgongo M, Uriyo JG, Damian DJ, Stray-Pedersen B, Msuya SE. Exclusive Breastfeeding up to Six Months is Very Rare in Tanzania: A Cohort Study of Infant Feeding Practices in Kilimanjaro Area Exclusive Breastfeeding up to Six Months is Very Rare in Tanzania : A Cohort Study of Infant Feeding Practices in Kilimanjaro. 2015;(August 2017).

22. Belay GM, Wubneh CA. Infant Feeding Practices of HIV Positive Mothers and Its Association with Counseling and HIV Disclosure Status in Ethiopia: A Systematic Review and Meta-Analysis. 2019;2019.

23. Ekubagewargies DT, Mekonnen HS, Siyoum TM. Assessment of Knowledge, Attitude, and Practice of HIV Positive Mothers on Antiretroviral Treatment towards Infant Feeding in Gondar Town Health Institutions. North West Ethiopia; 2017. 2019;2019.

24. Mnyani CN, Tait CL, Armstrong J, Blaauw D, Chersich MF, Buchmann EJ, et al. Infant feeding knowledge, perceptions and practices among women with and without HIV in Johannesburg, South Africa: a survey in healthcare facilities. 2017;1-9.

25. Alebel A, Tesma C, Temesgen B, Ferede A, Kibret GD. Exclusive breastfeeding practice in Ethiopia and its association with antenatal care and institutional delivery: a systematic review and meta-analysis. 2018;1-12.

26. Abraham C, Sheeran P. The Health Belief Model. 2016;(June 2015).

27. Odeny B, Pfeiffer J, Farquhar C, Igonya E, Gatuguta A, Kagwaini F, et al. The stigma of exclusive breastfeeding among both HIV-positive and HIV-negative women in Nairobi, Kenya. Breastfeed Med. 2016;11(5):252-8. 